\title{
EL "YO" DESDE EL PUNTO DE VISTA DE LA FILOSOFIA TRANSCENDENTAL
}

Herm Prof. Dr. Dr. h. c. Wolfgang Rod

He de pedirles disculpas de antemano por las inevitables deficiencias de mi uso del castellano. Confio, no obstante, en que el contenido de mi exposición será inteligible.

Siempre que aparece, en la Historia de la Filosofia, un pensamiento que hace época, es decir, que otorga una nueva dirección al pensamiento filosólico, puede contemplarse retrospectivamente desde dos puntos de vista: por un lado, podemos concentramos en su función de superar concepciones anteriores y acentuar la novedad; por otro lado, podemos contrastarlo con aquellas concepciones que surgen de el en el proceso posterior de desarrolto y acentuar los elementos que se muestran delicitarios y por ello necesitados de mejora.

De este doble modo puede contemplarse también la metafisica cartesiana, especialmente su primer axioma fundamental: Cogito ergo sum. Descartes puso en marcha con el Cogito como principio de una metafísica un cambio profundo: En lugar de la concepción de la metafisica como ciencia de la esencia de la realidad se abrió paso su concepción como ciencia que formula condiciones de posibilidad de conocimiento de la realidad. Ciertamente la metalisica cartesiana se halla relacionada aún en parte con la pregunta por la esencia de la realidad, pero por otro lado Descartes la entendió ya como doctrina de los principios del conocimiento.' Aunque la metafisica cartesiana tenía en parte aún la tarea de responder a las preguntas por la esencia de la realidad, apunta sobre todo al futuro en cuanto que asume también la función de una teoria de la experiencia, es decir, de una teoría que debe explicar cómo es posible el conocimiento de los objetos -especialmente el conocimiento científico. El desarrollo de la filosofia moderna se caracteriza por el despliegue de este último aspecto de la metalisica o de la Philosophia Prima, y además en relación con el supuesto de que las condiciones de posibilidad del conocimiento hay que buscarlas en el sujeto. Fue en Kant donde se planté por primera vez. esta concepción en su forma pura; más tarde se desarrolló entre otros en el neocriticisıno a finales del siglo xIx y comienzos del $\mathrm{x}$, en la fenomenologia trascendental y el racionalismo critico, en cada uno de ellos de un modo distinto.

Desde el punto de vista del neokantismo de la escuela de Marburgo, Paul Natorp 2 y Ernst Cassirer ${ }^{3}$ consideraron la concepción cartesiana como una prelormación de la filosolía trascendental, y de un modo parecido se representó a la luz de la fenomenología trascendental de Edmund Husserl. ${ }^{4}$ Esta interpretación ha quedado en la actualidad relegada a segundo término.

1 Descartes: Principes de la Philosophie; Letre preface; Oennres, edd. Ch. Adam y P. Tannery, Paris 18971910 (Nueva edición 1964-1967) (en adelante: AT) volumen IX/2. p. 14. Crf. Ibid, p. 16, donde se labla de los principios, cjuz pueden llamarse "filosofia primera" o "mutafisica".

2 Cfr. P. Natorp: Descartes' Erkemmmistheorie. Eine Studie zur l'orgeschichte ales Kritizismus. Marburg 1882: ders.: "Die Entwicklung Descartes" von den Regeln bis zu den meditationen". En: Archin fir Geschichte di't Philosophie, Vol. 10 (1897).

3 Cfr. E. Cassirer: Das Erkennmisproblem in der Philosphie und Hissenschaft der neucren Zeit. I. Darınstadt $197 !$ (Nueva impresión de la tercera cúción de 1922); eb.: Descartes. Lehre, Personliclikeit, Wirkung. Stockiholm 1939.

4 Cir. E. Hussetl: Erste Philosophie. H-II. Den Jlagg 1956 o 1959 (Ilusserliana VII-VIII). 
Aunque no es discutible que no fuera del todo adecuada, no hay que olvidar que se ajustaba más al planteamiento de Descartes que muchas otras interpretaciones concurrentes. Por eso vamos a enlazar con ella, pero al mismo tiempo queremos indicar también cómo se la puede superar en dirección a un criticismo más consecuente.

La importancia del Cogito cartesiano, como se ha dicho anticipadamente, se halla en que con él se inicia el cambio de la concepción de la metafisica como ciencia de la realidad a una concepción como teoria del conocimiento de la realidad. Pero no hay que pasar por alto que Descartes no pudo desarrollar consecuentemente las posibilidades abiertas con su punto de partida. Al no llegar a sus últimas consecuencias, ha podido ser interpretada de diversas maneras. De hecho, en la confrontación con la Philosophia Prima cartesiana se ha hecho hincapié unas veces en su dependencia de la filosofia tradicional, otras veces en su carácter innovador, a veces se ha entendido como subjetivismo, otras veces como una forma de objetivismo metafísico; unas veces se ha puesto el acento en el método de Descartes, otras veces en su ontología, etc. En la misma medida se dividen también los puntos de vista sobre la importancia del Cogito cartesiano.

Si se entiende el primer principio cartesiano como elemento de una metafisica de nuevo cuño, es decir, como parte de una teoria de la experiencia, ${ }^{5}$ entonces es necesario tener en cuenta también el desarrollo que se inició con el Cogito, y comparar la posición cartesiana en sus consecuencias posteriores más consecuentes. Aunque Descartes no fue capaz de sacar todas las consecuencias del nuevo comienzo, incluso oscureció algunos de sus aspectos, no hay que dejarse inducir a subrayar unilateralmente lo que retropectivamente se ha visto como incompleto o incluso como falso; más importantes es tener en cuenta cuál es el nuevo horizonte que Descartes abrió y qué importante fue el paso que él dio con el Cogito o con su filosofia en general.

En primer lugar paso, pues, a discutir la relación entre el cogito como comprehensión evidente o como acto lingüistico.

Como es sabido, el Cogito ergo sum es uno de los axiomas más discutidos de la filosofia. Aún cuando se acepta el Cogito ergo sum como un axioma del que no se puede dudar, no puede uno dejar de preguntarse en qué se basa su carácter indubitable. Sin pretender desarrollar esta discusión en todos sus detalles, queremos llamar la atención sobre dos interpretaciones diametralmente opuestas que se han defendido en relación al Cogito, a saber, la fenomenológica y la lingüistica. El comparar ambas interpretaciones nos va a servir para mostrar su caricter unilatcral y además para apuntar una posibilidad de ir más allá de ellas.

Mientras que en el marco de la filosofia analitica el Cogito ergo sum es comprendido mediante un análisis lingüistico, la concepción fenomenológica descansa en la comprehensión de la esencia del sujeto como fundamento de los actos que constituyen al objeto. Ambos puntos de vista no son mutuamente compatibles: desde el punto de vista behaviorístico no tiene ningún sentido el querer hablar sobre contenidos o actos de la conciencia; desde el punto de vista de la fenomenologia, por el contrario, está condenada al fracaso cualquier interpretación que pasc por alto el hecho de que los objetos de la experiencia o del conocimiento dependen de actos del sujeto. Vamos a recordar brevemente los fundamentos básicos de las interpretaciones citadas.

5 También Julián Pacho: Ontologie und Erkenntnistheorie. Eine Erorternung ihres l'erhallnisses am Beispiel des Cartesianischen Syssems. Manchen 1980, p. 23 s., habla de una función tearético-epistemologica del Cogito y ve en él una condición de posibilidad de todo axioms que describs circunstacias o hechos.

Sobre el papel de las teorias de la experiencia en la filosofia modema en general cfr. W. Rod: Evfallrung und Reflexion. Theorien der Erfahming in trans:endentalphilosophischer Sicht. München 1991. 
Según Husserl, Descartes habría subrayado con el Cogito "/a subjetividad cierta de si misma" y con ello habria dado el paso decisivo a la filosofia moderna. ${ }^{6}$ Husserl habló de un descubrimiento que consistia en que la subjetividad se halla cerrada en si de un modo absoluto -es decir, que no depende de algo exterior al sujeto-y puede llegar a saber de sí misma de un modo absolutamente cierto. ${ }^{7}$ De todos modos, Descartes, según Husserl, no fue capaz de hacer fructifero este descubrimiento porque no se preguntó cono el Ego constituy'e lat objetividad. Muchas cosas en Descartes, piensa Husserl, no se entienden y permanecen enigmáticas porque él no llegó a investigar la vida de la conciencia con su rendimiento en la constitución del objeto, como lo hicieron después Kant y, en el siglo xx, Husserl mismo.

Aunque a Descartes, según Husserl, le corresponde el mérito de haber colocado a la subjetividad, independientemente de toda referencia al objeto, como punto de partida de la filosofia ${ }^{8}$ concibió al yo, como Husserl le echa en cara, como un pedazo de mundo y por ello lo pudo constituir en punto de partida de conclusiones/argumentos causales que sirven para demostrar un mundo extemo independiente del pensamiento. Descartes habria descubierto realmente el "ergo puro", pero malentendió su esencia al concebirlo como alma, es decir, como un "pedazo del mundo objetivo", a partir del cual habría que buscar el acceso a los objetos del mundo. 9 Por esta razón se convirtió en defensor del realismo trascendental, que fue rechazado, con mazón, por Kant. ${ }^{10}$

Aunque hay que dar la razón a Husserl respecto a la critica a la concreción cosificadora del yo, comete él, desde otro punto de vista, el mismo error que achaca a Descartes: Husserl carncteriza al yo -y precisamente al yo puro de la filosofia, no al yo de la psicologia- como algo que puede describirse, no como objeto de la descripción cotidiana o cientílica, pero sí como tema de una descripción fenomenológica. En su opinión, el Ego se concibe como yo trascendental, es decir, como aquello que constituye los objetos de la experiencia o del conocimiento en su sentido de ser; es observador del Ego que se refiere a objetos. Evidentemente el yo trascendental es, según Husserl, en cierto modo observable, aunque desde la perspectiva trascendental no debe ser entendido como objeto de la observación. Esto ser toma especialmente claro, cuando Husserl ten referencia al yo trascendental, habla de un "reino de la autoexperiencia trascendental-fenomenológica"."1

Ciertamente, Husserl no fue por el camino de la objetivación tan adelante como Descartes, el cual creyó poder captarlo no sólo como existente, sino también como sustancia; 12 pero si que dio un (primer) paso por el camino tomado por Descartes. Por ello su critica a Descartes no es suficientemente radical; todo depende de distanciarse de la concepción del yo como un posible objeto de experiencia.

El supuesto de que el yo sea un posible objeto de experiencia ha sido puesto en entredjcho de un modo decisivo por los defensores de la filosofia analítica. La interpretación analitica del primer principio cartesiano la la defendido de un modo especialmente sorprendente Jaakko Hintikka. ${ }^{13}$ Según su opinión, el Cogito no es indudable a causa de la introspección,

6 Ilusserl: Erste Philosophie (1923/24). Primera parte: Kritische Ideengeschichte. Ilusserliana, vol. VIl, p. 61.

7 bid. p. 63.

8 Ibid.p. 73 .

9 Ibid. p. 73. Cfr. Julión Pacho, 1.c., p. 20: "El Yo al que se hace referencia en la frase del Cogito, es un ser del mundo resl". (En el original en cursiva.)

10 Husserl: Cartesianische Meditationen und Paris Vortroge, Husserliana, vol. I, p. 9.

"Ilusserl, 1.c., p. 65. La citada aproximación vale para olras parecidas con el mismo sentido.

12 Med. III: AT Vil, p. $34 ;$ ctr. p. 45.

13 J. Hintikka: "Cogito, ergo sum: Inference or Performance?" In: W. Doney (ed.): Descantes. A collection of critical essays. London y Melbourne 1968, p. 108ss., esp. 9, p. 124 ss. 
sino porque se trata de una expresión lingüistica que se justifica completamente a si misma. Así como alguien que dice "Yo no digo ahora nada" invalida esta expresión por el hecho de que dice algo, asimismo se anula también la expresión "Yo no pienso ahora nada" se se piensa bien. $Y$ al revés, la negación de esta expresión —es decir, "yo pienso ahora"- se confirma en su misma realización lingüistica; lo mismo ocurre con "yo voy". El Cogito ergo sum afecta scgún Hintikka solamente a relaciones en el ámbito de la expresión linguistica, es decir, en el ámbito del comportamiento humano, no a relaciones en el ámbito de la conciencia, como habia pensado Descartes, cuya concepción seria ilusoria desde esta punto de vista.

Una interpretación del "Cogito", tal como la ha propuesto Hintikika, tiente evidentemente consecuencias demoledoras para la metafisica cartesiana: No es posible fundamentar ningún sistema filosófico en un axioma que valga sólo porque no se puede dudar razonablemente de él por motivos lingüisticos. El Cogito tiene que tener una dimensión más amplia si quiere presentarse como un principio.

Las reservas de la filosofia analitica contra el supuesto de que el yo sea algo que pueda observarse en la reflexión o que por lo menos sea algo cuyas circunstancias y acciones sean observables, hay que tomarlas en serio. Una concepción como la que ha defendido Husserl, dificilmente puede ya ser la nuestra. Pero también la posición contraria la analítica, tiene dificultades. Si el Cogito fuera sólo una expresión cuya negación es perfornativamente inconsciente, entonces no podria tomarse como primer axioma porque de él no pueden deducirse aquellas conclusiones a las que Descartes creyó poder llegar, o sea, de un modo más general: porque ya no es posible como parte de una teoria de la experiencia.

Pero la situación no es tal que haya que aceptar o el punto de vista de la reflexión o el de la interpretación lingáistica; hay una concepción que evita las unilateralidades de la filosofia de la conciencia asi como la interpretación puramente linguistica y que además permite olorgar a Descartes, de un modo más claro de lo que fue capaz Husserl, un puesto en la prehistoria de la filosofia trascendental. Esto es posible si se renuncia a concebir cl Ego como objeto. Si se toma en serio la idea de que el "yo" no significa nada objetivable, sino lo que tiene que pensarse necesariamente como correlato del mundo objetivo, entonces pueden evitarse no sólo las debilidades de la interpretación de Husserl, sino que además se le resta el suelo a la crítica analítica a la concepción mentalista del Cogito.

Sin embargo, antes de apuntar la posibilidad de una interpretación que sea capaz de escapar a la tentación de una concepción objetivista del Cogiro, vamos a poner de relieve el aspecto de la concepción cartesiana que más nos interesa en este contexto.

\section{Así, pues, el carácter del Cogito en Descartes.}

Para hacer justicia al papel que juega el Cogito en la metafisica cartesiana, hay que tener presente que, para Descartes, se trata de justificar la pretensión de validez objetiva vinculada a determinados axiomas -especialmente a los axiomas de la ciencia matemática-. Además hay que tener en cuenta que a él el problema de la validez objetiva se le representó bajo la presuposición de que se nos hacen presentes a nosotros sólo contenidos de representación ("ideas"), y no algo a lo que las ideas se refieren o lo que se representa por medio de las ideas.

Esta presuposición - el idealismo- implica el peligro de un cierto modo de escepticismo: parece poder dudarse de que las ideas se refieran a algo independiente del pensamiento. Los criterios de objetividad de las ideas podrian ser sólo caracteristicas de las ideas misınas; pero si las ideas tienen un carácter meramente subjetivo, entonces también sus características son subjetivas y por ello son incapaces de garantizar la objetividad. Sin embargo, en la vida 
cotidiana estamos convencidos de que en las ideas o en los juicios captamos algo de una realidad que existe independientemente de nosotros, y esta misma convicción acuña el pensamiento de los científicos. Descartes creyó que esta convicción es justa, es decir, consideró equivocado el escepticismo del mundo externo. Por ello se preguntó cómo se puede superar este escepticismo, y la respuesta la encontró sólo en el marco de una teoría que fuera más allá de los límites de las ciencias particulares, es decir, en el marco de una teoria metafisica que se diferenciara de las teorias cientificas en que no sirve para explicar hechos dentro del mundo, sino que tiene que hacer comprensible cómo es posible el conocimiento de los hechos.

El Cogito es una parte de esta teoria, y sólo como tal puede entenderse adecuadamente. En consecuencia, todos los intentos de analizar el Cogiro como axioma aislado, se quedan cortos - bien se lleven a cabo en el marco de la filosofia de la conciencia o con los medios del análisis lingüístico.

A la hora de formular la teoria que Descartes desarrolló bajo el nombre de Philosophia Prima, se parte del hecho de que nosotros pretendemos experimentar o conocer algo. Que nosotros experimentamos algo, y además como objeto, como cosa, no puede ponerse en duda; dudable es sólo qué estatuto ontológico tiene lo que experimentamos. Se puede pensar que fuera de nuestras ideas no experimentamos nada, es decir, que no existe ningún mundo externo material ni ámbito alguno de entidades ideales ("naturalezas verdaderas e incambiables"). Creemos de un modo natural que a nuestras representaciones de las cosas les corresponden objetos materiales, y algunos - como Descartes- creen también que a nuestros conceptos distintos se le hallan ordenados objetos abstractos. Suponemos que a los objetos representados les corresponde una realidad independiente de nuestro pensamiento (realitas formalis), pero toda suposición de este tipo, como se pone en evidencia en la duda metódica, es insegura. Por lo tanto queda abierta la cuestión acerca de si la representación se limita a contenidos de la conciencia o si trasciende la conciencia en determinadas circunstancias.

En principio sólo se puede decir lo siguiente: que la realidad del yo no puede ponerse en duda. Ego sum, ego existo - esto es necesariamente verdadero. ${ }^{14}$ Con la constatación de que yo soy, no puede bastar; todo depende de conocer lo que y'o soy, es decir, de definir lo que constituye mi esencia. Partiendo de lo que se ofrece de un modo natural y espontánto al pensamiento, Descartes eliminó del concepto del sujeto todo to que no le pertenece necesariamente. ${ }^{15}$ La conciencia, la sustancialidad y la finitud es lo que queda restante, de modo que Descartes pudo pasar del Ego sum al Sum substantia cogirans, entendida como substantia cogitans finita. Al paso del Cogito al Sum res cogitans le subjace la idea de que los fenómenos mentales (cogitationes) pueden ser concebidos sólo como circunstancias de una sustancia, cuya esencia consiste en la conciencia (en la cogitatio). Sin el principio de la sustancialidad no seria posible este paso. Se ha subrayado siempre el hecho de que Descartes no hay cuestionado principios como el de la sustancialidad; este hecho pone en evidencia que el escepticismo metódico cartesiano no suponía una duda en la validez de los principios ontológicos, sino fundamentalmente era duda en la objetividad de las ideas y de los juicios.

Acentuar la finitud de la sustancia pensante es esencial para las pruebas de la existencia de Dios en las que se da el paso más allá del ámbito de los objetos meramente representados. En el argumento de que lo infinito tiene que existir si se da el yo finito pensante, entra en juego un principio que se halla sometido tan poco a la duda metódica como el principio da la sus-

\footnotetext{
14 Mled. II; AT VII, 25.

is Cfr: Med. [1; AT VII, 25 s.: “subducan quicquid... potuit infonnari".
} 
tancialidad, a saber, el principio del primado de lo infinito sobre lo tinito. Lo actuamente infinito, es decir, Dios, se capta en cierto modo antes que el yo finito. ${ }^{16}$ El concepto de un ser finito $-y$ también del yo finito- se forma por resticción del concepto de lo infinito, el cual, en cuanto condición de los conceptos de los seres finitos, es anterior a esos conceptos. 17

Ambos prinicipios mencionados pertenecen, junto con el principio de causalidad, a aquella ontologia en cuyo marco Descartes demuestra la existencia de Dios como un ser verdadero, incapaz de engañar. El Dios verdadero garantiza la validez objetiva de todos los juicios evidentes: si estos juicios fueran falsos, estariamos sometidos a un error inevitable y seriamos enganados por Dios como el creador de nuestra naturaleza. Juicios que son evidentes porque contienen sólo conceptos distintos no pueden por ello ser falsos; Descartes puso su mayor empeño en demostrarlo. El Cogito es sólo un paso en el camino hacia este resultado: Descartes no queria fundamentar una filosofia subjetivista, sino justificar la pretensión de validez objetiva de los juicios evidentes. El retroceso hacia la autocerteza del pensamiento es a sus ojos un rodeo necesario para llegar a la meta indicada.

Los principios ontológicos citados parecen ser supuestos independientes de la teoria cartesiana del conocimiento de la realidad; pero de hecho su validez descansa en que la teoría a la que pertenecen funciona, es decir, en que con su ayuda puede aclararse por qué determinados juicios son objetivamente válidos. Como Descartes no veja ninguna alternativa a su teoria de la validez objetiva, consideró principios absolutamente válidos a los aviomas que la formaban. En una visión retrospectiva se puede mostrar que Descartes esbozó sólo una de las múltiples teorias posibles. Pero si los principios de la metafisica cartesiana hay que relativizarlos en función de una determinada teoria de la experiencia, no se les puede otorgar validez absoluta.

Entro a exponer los rasgos trascendentales en la teoria cartesiana de la experiencia. Descartes, al concebir, como se ha dicho, la metafisica como doctrina de los principios del conocimento de la realidad, en cierto modo, preparó el camino a la filosofia trascendental. Descartes llegó ya a pensar que las cosas no pueden experimentarse independientemente del entendimiento, incluso que el concepto de cosa en general incluye la relación con el entendimiento. Acentuó que la experiencia de la cosa no consiste en recibir impresiones sensibles (como ver, tocar, etc), pues contiene siempre un juicio. ${ }^{18} \mathrm{El}$ juicio sin el que no podria hablarse de experiencia de la cosa, hace referencia por un lado a la pertenencia de las múltiples propiedades observables a uno y el mismo objeto; por otro lado, se refiere a la unidad de la cosa en el cambio de sus estados.

El hecho de que la unidad de la cosa se basa en el juicio lo ha ilustrado Descartes con ayuda de la comparación de las propiedades de una sustancia con los vestidos que - a diferencia de los que las llevan- se ven. Asi como en determinadas circunstancias se perciben sólo los vestidos, pero no las personas que los lleven, asimismo la percepción nos muestra siempre sólo las propiedades, pero no la sustancia que tiene tales propiedades. Si nosotros, como de becho es el caso, experimentamos las cosas como unidades en la diversidad de sus propiedades, no puede tratarse meramente de recibir impresiones por medio de los sentidos, sino que se trata de una experiencia en la que participa el entendimiento.

16 Med. III; AT VIl, 45: "... priorem quodanmodo in me esse perceptionem infiniti quam finiti, hoc est Dei quam mei ipsius".

17 A Clesselier, 23 de abril de 1949; AT V, 356.

18 Aled. II; AT VII, 32: “... id quod putabam me videre oculis, sola iudicandi facultate ... compreltendo". 
Del mismo modo, la identidad del objeto en el tiempo, apunta a un acto del entendimiento. Aunque dentro de un intervalo de tiempo todas las propiedades de una cosa - por ejemplo, la temperatura, el color, la solidez, la forma, el volumen de un trozo de cern- pueden cambiar, hablamos de una y la misma cosa. Como lo hacemos incluso cuando ninguna de las propiedades observables permanece igual, la unidad no puede ser una determinación que se pueda percibir; es pensada por medio del entendimiento, y en este sentido la experiencia del objeto idéntico se basa en un acto del entendimiento. ${ }^{19}$

Del resultado de este anólisis, Descartes sacó la consecuencia que yo, siempre que sé dé un objeto, sé también de mi como sujeto racional de esta experiencia, incluso aclaró que nosostros nos captamos a nosotros mismos hasta de un modo incluso más fảcil y con mayor evidencia que a las cosas. ${ }^{20}$ Esta constatación es sorprendente no sólo porque Descartes mismo haya subrayado las dificultades de un autoconocimiento adecuado, 21 sino porque él también vio que primero captamos las cosas y luego a nosotros mismos. $\mathrm{Al}$ afirmar que al autoconocimiento le corresponde el primado antes que a la conciencia del objeto, esta constatación tiene que resultar de otro punto de vista que la anterior. La distinción entre "anterior para nosotros" y "anterior en si" no basta; más bien se distingue entre un primado al nivel de la experiencia y un primado al nivel de la teoría de la experiencia, es decir, en el nivel trascendental: sólo en este último nivel el autoconocimiento es anterior y más evidente que el conocimiento de objeto alguno. En la afirmada evidencia del autoconocimiento no se puede tratar de una evidencia que se refiera a la esencia del Ego, sino sólo de un conocimiento trascendental, de que independientemente del entendimiento nada puede experimentarse como objeto, incluso ni siquiera pensarse como objeto. Este conocimiento resulta sólo en la rellexión sobre la experiencia, es decir, en el contexto de la pregunta bajo qué condiciones puede considerarse posibla la experiencia del objeto.

Al hecho de que nosotros nos cercioremos de nosotros mismos no de un modo inmediato, sino por medio de la experiencia de los objetos, a este hecho apunta la constatación de que, al experimentar cosas corporales, reconocemos también nuestro espiritu. ${ }^{22}$ La idea de que la autocerteza se halle mediada por la certeza del objeto, no le era pues ajena a Descartes; la expresa también cuando se dice que queda excluido el que yo mismo cuando veo o (...) cuando tengo la conciencia de ver, no sea algo como pensador.23 "Ver" hay que entenderlo aqui en el sentido de "ver algo", e igualmente "la conciencia de ver" en el sentido de la "conciencia de ver algo". Esto vale para el Cogito, en general. La formulación de este principio es: Ego cogito, o sea en una formulación más fuerte: "Yo pienso los objetos como constantes en el tiempo y como unidades de diversas propiedades dadas por los sentidos, luego soy un yo que realiza juicios, un y'o racional".

El modo en que Descartes interpretó este saber mediado del yo hace de él clarantente un precursor de la filosofia trascendental: en la experiencia del objeto sabemos acerca de nosotros mismos, ya que los objetos no pueden experimentarse sin el entendimiento, el cual unilica lo

19 Ebenda, 31: "solius mentis inspectio".

20 Ebenda, 33: "si iudico ceram existere, ex eo quod hane videarn, certe multo evidentius eflicitur me ipsum etiam existere".

21 Cfr. Matial Guerolut: Descartes selon Yordre des raison, l: L'âme et I letu. Paris 1953, p. 127.

22. Aled. II; $\wedge T$ VII, 33: “... ex co qutod intelligantur (scil. Corporal) aperte cognosco nilil facilius aut evidentius meâ mente nosse a me percipi".

23 Jbid, 33: “... fieri plane non potest, cum videam, nive (...) cum cogitem me videre, ut ego ipse cogitons non alquid Sim". 
diverso. Descartes rozó sólo la idea de que la experiencia del objeto suponga una síntesis del entendimiento: pero el hecho de que la rozara permite hablar de un primer paso hacia la filosofia trascendental.

Alıra se verá claramente por qué la interpretación lingüistica del primer principio curtesiano es insuficiente: no puede justificar el aspecto trascendental del Cogito cartesiano. Si sólo podemos hablar sobre las cosas porque el yo es un sujeto pensante, más concretamente juzgante y, en este sentido, espiritual o intelectual, entonces hay que entender el primer-principio cartesiano como un axioma que hace referencia a las condiciones bajo las que puede hacerse comprensible la experiencia de los objetos.

Asi como la modernidad del principio cartesiano tiene su fundamento en su pertenencia a la historia del trascendentalismo, asimismo se explican los puntos débiles de este principio por la consecuencia deficiente en la realización del punto de vista trascendental, a saber, en el aferramiento a la creencia de que el yo es una forma de objeto, el cual puede ser experimentado como tal. Si Descartes hubiera no sólo rozado, sino además desarrollado la idea de que el entendimiento que juzga es condición de la experiencia del objeto, es decir, que el objeto depende del yo que juzga, entonces no hubiera sucumbido a la tentación de concebir al yo como res o como substantia, sino que lo hubiera definido claramente como aquello para lo que existen las cosas o substancias. Como no lo hizo, su concepción se ve sometida de hecho a las objeciones que le han planteado Husserl y otros.

En la vista de este diagnóstico, puede preguntarse cómo hay que modificar la concepción cartesiana para que no se vea sometida a las reservas indicadas. Tras lo dicho hasta ahora, es claro que todo depende de evitar la interpretación del yo como res y la interpretación del contenido de la representación como realitas - a saber, como realitas objectiva.

El yo se presenta primeramente como correlato de la realidad objetiva; es aquello para lo que hay objetos, por ello él mismo no es objeto. En consecuencia, no es necesario interpretarlo como objeto de la reflexión. Si se concibe como tal y se define como res cogitans, como une chose qui pense, cntonces ya se da una interpretación. Esta interpretación es la consecuencia de una presuposición cognoscitiva fundamental, a saber, de la tesis de que todo lo que se representa, se representa como cosa. En este sentido, Descartes designó a las ideas al mismo tiempo imágenes de las cosas, 24 y aclaró que no podemos concebir más que bajo la forma de una cosa que existe. ${ }^{25}$ Como según Descartes también del yo sabemos sólo por medio de una idea, 26 tienen que valer también de esa idea lo que Descartes supuso de las ideas en general: sólo pucde representar al yo como algo cosificado. Como Descartes tomó como un axioma que tiene valor universal el supuesto de que las ideas siempre son ideas de cosas, resulta que lo no cosificable no puede pensarse ni mucho menos experimentarse ni conocerse.

El supuesto de que el yo, lo mismo que Dios, puede ser concebido como objeto, deja reconocer el influjo de una cierta tradición ontológica; pero al mismo tiempo tiene que referirse a una teoría cartesiana del conocimiento de la realidad que fundamenta en general la posibilidad de juicios objetivamente válidos en la idea de un orden racional de la realidad fundado en Dios. Segủn Descartes, la concordancia de las estructuras del pensamiento con las estructuras del

24 Med. Ill; AT VIl, 37: "tanquam imagines rerum". Lo mismo AT VII, 44: “... nullac idea nisi tanquam rerum esso possunt...".

25 line Resp., app., ax. X; AT VIl, 166.

26 Med. III; AT VII, 42: (idea) "quae me ipsum mibi exhibet..." 
mundo es posible porque la sustancia finita pensante y la sustancia corporal se hallan unidas debido a su dependencia mutua de una sustancia divina infinita. Tal conexión la pudo captar Descartes sólo como conexión de esencias sustanciales, y por ello tuvo que concebir también al yo como sustancia. La concepción sustancialista del Ego es pues una interpretación condicionada por el marco de la teoria de la experiencia y debe por ello relativizarse a ésta.

Lo mismo ocurre con el supuesto de que el objeto inmediato de la conciencia sea el contenido de una idea. Este punto de vista - el citado idealismo- no fue Descartes el primero que lo introdujo, sino que se formó históricamente. ${ }^{27}$

Sin embargo, Descartes no presupuso simplemente el idealismo, sino que intentó hacerlo plausible con ayuda de argumentos, al apuntar que nosotros - en el caso de las alucinaciones y de los suenos- pensamos percibir un objeto independiente del pensamiento, sin embargo en realidad sólo estamos ante contenidos de las representaciones. Aunque se le reconozca un alto grado de plausibilidad a las ideas de Descartes y aunque se tenga presente que el supuesto idealista en la filosofia moderna ha sido muchas veces considerado como evidente, hay que tener en cuenta que se trata de una interpretación que no es indudable. Lo que de hecho percibimos son cosas, no representaciones; las representaciones no pueden de ningún modo ser experimentadas inmediatamente; suponemos que existen ideas para poder aclarar ciertos hechos - como el hecho de la alucinación.

Una vez liberado de estos supuestos es posible concebir al "yo" y a las "representaciones" como conceptos construidos y no empiricos. Si se toma la metatisica cartesiana como una teoria con cuya ayuda debe concebirse la experiencia como posible, entonces pueden concebirse los conceptos del yo, de las ideas (como quasi-objetos inmanentes a la conciencia) y del entendimiento instaurador de unidad como construcciones que se hallan al servicio de la teoria de la experiencia. Los conceptos construidos y los axiomas fundamentales formulados con su ayuda se justifican por su papel en esta teoria, y no por su evidencia. Por ello no es necesario suponer que se reflexione sobre el yo como algo objetivo, que las representaciones son una forma de imágenes en la conciencia o que los actos de la conciencia se pueden observar.

De tal concepción surge la consecuencia de que el Cogito no hay que referirlo a algo experimentable introspectivamente y no hay que concebirlo como expresiön de una mirada esencial, de una intelección en la verdadera naturaleza del espíritu. El Cogito ergo sum tiene que valer más bien como parte de una teoria que se esboza para hacer comprensible que podemos conocer algo de la realidad fuera de nuestro yo.

Alora podemos responder a la pregunta qué significan "cogito" y "sum": cogitare tiene el sentido de "percibir un objeto por medio del entendimiento o sea del juicio"; y "sum" significa que el concepto del yo es indispensable para comprender la posibilidad de la percepción de objetos. El "sum" expresa un acto del intelecto - solius mentis in spectio-, como el conocimiento de un trozo de cera, según el ejemplo ya citado.

La modificación indicada acabaría en una metafisica de nuevo cuno - una metafisica com teoria de la experiencia, pero sin apelar a la evidencia o a la contemplación de la esencia, por eso también sin pretender valer definitivamente. Descartes no ha podido alcanzar el punto de vista de tal metafisica; pero ha dado un paso que apunta a su dirección y por eso ha inaugurado una época de la historia de la filosofia que - a pesar de todas las proclamas postmodernas- aún no ha llegado a su fin. 28

27 Cfr. p.e. llae Resp., appendix, def. Il; $\Lambda$ T VIl, 160: "Por idea entiendo la forma de toda concienci:t por imedio de cuya percepción inmediata soy consciente precisamente de esta conciencia.

28 Traducción del Dr. Xabier Insausti. Correcciones del Dr. Juliân Pacho 